\title{
0 sistema de comissões brasileiro: elementos para uma agenda de pesquisa
}

\author{
The Brazilian committee system: elements for a research agenda
}

\author{
Emerson Oliveira do Nascimento \\ Professor de Ciência Política do Instituto de Ciências \\ Sociais, Universidade Federal de Alagoas - UFAL, \\ e-mail: emersondonascimento@yahoo.com.br
}

Recebido: 03/10/2012

Aceito: 28/01/2013
RESUMO Os estudos sobre o Congresso norte-americano compõem, indiscutivelmente, o mais, teoricamente e metodologicamente avançado subcampo da Ciência Política contemporânea. A contribuição destes estudos para o desenvolvimento de uma teoria geral do legislativo tem sido mais limitada, visto que, baseados em pressupostos comportamentalistas, tais estudos foram desenvolvidos dentro de um contexto institucional que difere dramaticamente daquele encontrado em virtualmente todas as outras democracias presidenciais. Nestes termos, acreditamos que a pressuposta universalidade da sua aplicação seja deveras questionável. $\mathrm{O}$ argumento desenvolvido aqui é que as fundações epistemológicas das teorias positivas da organização legislativa norte-americana não são universalmente traduzíveis para qualquer contexto institucional. Em se tratando do estudo do sistema de comissões do Congesso Brasileiro, procura-se explorar as consequências da adesão indiscriminada aos pressupostos da agenda norte-americana e os vícios de interpretação produzidos até então. Finalmente, argumenta-se a favor de uma adaptação flexível e parciomoniosa destes modelos, repeitando-se, naturalmente, suas especificidades.

Palavras-Chave Estudos legislativos; Teoria positiva; Sistema de comissões.

ABSTRACT Studies of the U.S. Congress make up arguably the most theoretically and methodologically advanced subfield of contemporary Political Science. The contribution of these studies to develop a general theory of the legislature has been more limited, since, based on behavioral assumptions, such studies have been developed within an institutional context that differs dramatically from that found in virtually all other presidential democracies. Accordingly, we believe that the assumed universality of its application is indeed questionable. The argument developed here is that the epistemological foundations of positive theories of legislative organization U.S. are not universally translatable to any institutional context. In terms of system study committees Brazilian Congress attempts to explore the consequences of indiscriminate adherence to the assumptions of the American agenda and the vices of interpretation produced so far. Finally, it is argued in favor of a flexible adaptation and parsimonious this model, regard is, of course, their specificities.

KEYWORDS Legislative studies; Positive theory; Commissions system. 


\section{Apresentação}

Os estudos sobre o Congresso norte-americano compõem, indiscutivelmente, o mais, teoricamente e metodologicamente avançado subcampo da Ciência Política contemporânea. Não obstante, enquanto este subcampo tem de modo convincente, aperfeiçoado nossa compreensão das instituições congressionais norte-americanas, sua contribuição para o desenvolvimento de uma teoria geral do legislativo tem sido mais limitada (Gamm e Huber, 2002).

As teorias norte-americanas baseadas sobre pressupostos comportamentalistas, foram desenvolvidas dentro de um contexto institucional que difere dramaticamente daquele encontrado em virtualmente todas as outras democracias presidenciais, o que implica que a pressuposta universalidade da sua aplicação venha sendo questionada ${ }^{1}$. Nesse ínterim, a discussão sobre a natureza e o funcionamento do sistema de comissões tem sido transladada para o contexto das nossas instituições nos moldes das três principais tradições que orientam hoje a discussão norte-americana sobre os princípios da organização legislativa (distributiva, informacional e partidária) ${ }^{2}$.

Considerando que entre o desenho institucional norte-americano e as demais democracias presidenciais há dessemelhanças quase intransponíveis, alguns estudiosos argumentam que as teorias desenvolvidas para o estudo do Congresso americano, são pouco úteis para explicar o funcionamento das legislaturas sob outros contextos institucionais (Weyland, 2002). $\mathrm{O}$ argumento desenvolvido aqui é que as fundações epistemológicas das teorias positivas ${ }^{3}$ da organização legislativa norte-americana não são universalmente traduzíveis para qualquer contexto institucional, mas são suficientemente robustas e flexíveis para serem adaptadas sob alguma parcimônia a outros cenários institucionais além do americano.

Este artigo pretende se deter sobre as principais lacunas encontradas na literatura recente sobre o estudo da organização legislativa brasileira e, subsequentemente, o papel desempenhado ou não pelo sistema de comissões brasileiro. Levando em conta que nenhuma destas tradições (distributiva,

\footnotetext{
Limongi já realçou os limites dessa adesão indiscriminada a muitos pressupostos da agenda norte-americana no contexto dos estudos da política comparada. Cf. Limongi (2003).

2 Sobre a influência das tradições norte-americana sobre a ciência política brasileira Cf. Santos (2006) e Limongi (1994).

Por teorias positivas entendo aqui o conjunto de teorias sobre o Congresso norte-americano desenvolvidas com base em pressupostos comportamentalistas ou neo-institucionais, mas que possuem em comum a prescrição de postulados empiricamente motivados e acompanhados de suas respectivas corroborações e refutações. Cf. Austen-Smith e Banks (1999); Shepsle e Weingast (1994).
}

informacional e partidária) firmou-se de maneira conclusiva entre os estudiosos do Congresso Nacional, procuro explorar até onde a adesão indiscriminada aos pressupostos da agenda norte-americana produziu interpretações viciosas acerca do legislativo nacional ${ }^{4}$, e elaborar aquelas que possam vir a ser possíveis evidências sugestivas de pesquisa acerca do que seriam as reais ${ }^{5}$ fundações institucionais do sistema de comissões brasileiro ou como, pelo menos, explicar sua existência e funcionamento dentro do legislativo nacional.

\section{Revisitando algumas proposições sobre 0 sistema de comissões}

A questão central da organização legislativa, a saber - como alinhar os interesses paroquiais dos legisladores de modo a evitar os efeitos deletérios da racionalidade individual sobre a produção do bem comum - tem recebido várias interpretações ao longo do tempo. Analisando o desenvolvimento das teorias positivas da organização legislativa, é difícil ignorar o papel explicativo que elas têm reservado ao sistema de comissões, visto como a variável principal para explicar a consecução de resultados estáveis e o processo interno de tomada de decisões (decisionmaking). Para a maioria destes autores, adeptos ao novo institucionalismo, as comissões constituem importantes mecanismos que facultam a produção de decisões estáveis, contrapondo-se, portanto, ao caráter cíclico da regra majoritária e à ameaça de paralisia decisória dela decorrente ${ }^{6}$.

\footnotetext{
${ }^{4}$ Limongi (2003) ilustra o problema da incompatibilidade de pressupostos no campo da política comparada aludindo ao mito de Procustos que, segundo a mitologia grega, usava uma mesma cova para colocar deitadas suas vítimas, cortando-lhes as pernas ou esticando-as de forma a ajustá-los "perfeitamente" à cova.

5 Refiro-me aqui à idéia de que existe uma realidade exterior, ontológica e independente do ser e das possíveis concepções que se tenha dela. Neste sentido, parto do pressuposto que a realidade pode ser estratificada sob níveis distintos - o empírico, o factual e o real. O domínio empírico seria aquele acessado via por experiências via observação direta. O domínio factual incluiria não apenas experiências, mas também eventos que podem ou não ser observados (por serem muito pequenos/grandes/rápidos/lentos, etc. para serem percebidos pelos instrumentos de observação disponíveis). E finalmente, o domínio do real, o qual incluiria os mecanismos, isto é, os processos invisíveis ou as estruturas subjacentes que gerarim os eventos. Cf. Bhaskar (1996); Hamlin (2000).

${ }^{6}$ Para a "nova" tradição institucional, ao contrário da "velha" tradição institucional, instituições são vistas não como o produto residual de estruturas sociais ou o resultado de uma soma pura e simples das preferências individuais. O novo paradigma institucional concorda que instituições são criações conscientes de atores sociais dotados de crenças e preferências, por isso mesmo, instituições são compreendidas ao mesmo tempo como um produto das intencionalidades individuais e também, um espaço de embate entre os atores, posto que instituições podem privilegiar grupos particulares em detrimento dos demais. Cf. Lecours (2005); Immergut (1998); DiMaggio e Powell (1991).
} 
A literatura produzida pela escola da escolha racional $^{7}$ sobre o funcionamento do sistema de comissões no Congresso norte-americano baseia-se no modelo Principal-Agente, no qual um Principal delega tarefas para um Agente num ambiente de informação assimétrica ${ }^{8}$, de modo que o bom funcionamento da relação depende de uma estrutura de incentivos que alinhe os interesses de ambas as partes. Por conseguinte, podemos afirmar que três grandes questões distinguem uma das outras as teorias positivas das instituições congressionais. A primeira questão é a identidade do Principal para os quais as comissões servem como Agentes. Para a teoria distributiva, as comissões servem aos interesses dos distritos eleitorais (district constituents) de seus representantes, que usam o sistema como forma de obter ganhos de troca (gains from trade $)^{9}$. Para a teoria informacional, o Principal é a Câmara ou o plenário como um todo, o qual concederia certos poderes às comissões como incentivo para que se especializem (expertise), adquiram informação e passem esta informação para o plenário ${ }^{10}$. Finalmente, a teoria partidária, vê o partido majoritário como o Principal. Segundo seus adeptos, as regras legislativas concedem ao partido majoritário uma série de poderes especiais que são usados para controlar as ações das comissões em prol do interesse dos membros do partido (cartel theory) ${ }^{11}$.

A segunda questão diz respeito às motivações ou aos objetivos. Razoáveis motivações têm sido propostas aos vários Principais. Diz-se que distritos perseguem benefícios federais (pork barrel); que os membros das Câmaras procuram reduzir as incertezas sobre os

\footnotetext{
Por escola da escolha racional, faço referência ao conjunto de pressupostos amplamente divulgados na Ciência Política e, sobretudo no subcampo dos estudos legislativos, que partem da proposição de que o comportamento coletivo pode ser explicado em termos de atores que procuram atingir seus objetivos. Estes podem ser indivíduos isolados ou grupos, o que importa é que tenham objetivos a atingir, e que o façam racionalmente, ou seja, mediante a escolha de meios adequados à consecução dos fins. Cf. Coleman (1998) e Elster (2000).

${ }^{8}$ Relações de delegação são, por natureza, relações hierárquicas. Para entendê-las, utilizamos o chamado modelo principal-agente, oriundo da teoria das organizações industriais, mas hoje amplamente utilizado pela Ciência Política. O modelo tem dois jogadores, um Principal que delega tarefas e um Agente que deve implementá-las. As interações ocorrem em um espaço unidimensional onde o Principal tem um ponto ideal $x P=0$ e o Agente tem um ponto ideal $X A ́>x P$. A lógica do jogo é buscar reduzir ao máximo as oportunidades de comportamento oportunista por parte do Agente e assim, garantir a consecução dos interesses do Principal. Cf. Kiewiet e McCubbins (1991); Bendor e Meirowitz (2004)

${ }^{9}$ Sobre os pressupostos fundacionais da teoria distributiva Cf. Shepsle (1978); Weingast e Marshall (1988)

${ }^{10}$ Acerca dos modelos de racionalidade informacional Cf. Krehbiel (1991).

${ }^{11}$ Sobre a tradição partidária e a teoria do cartel Cf. Cox e McCubbins (1993); Kiewiet e McCubbins (1988).
}

resultados das políticas; e que os líderes partidários procuram proteger ou aumentar a reputação do seu partido. De acordo com estas teorias, os membros das comissões priorizariam, respectivamente, suas chances de reeleição, a aquisição de informações sobre os resultados de políticas ou as próprias escolhas de políticas (maximizando suas oportunidades frente ao partido).

A terceira questão compreende os limites da dimensionalidade. A complexidade das questões e a presença de maiorias mínimas são problemas para qualquer grupo de Principais, sejam estes os distritos, os parlamentares ou os membros de um partido. No geral, estes problemas compreendem os limites da consecução da ação coletiva ${ }^{12}$ entre estes grupos, dos quais, o mais frequiente é o problema da formação de maiorias cíclicas ${ }^{13}$, sobretudo quando o espaço político é caracterizado por duas ou mais dimensões.

Todavia, a despeito do papel mais ou menos privilegiado que cada uma das teorias (distributiva, informacional e partidária) reserva às comissões, elas conferem diferentes finalidades para elas: segundo o modelo distributivista, as comissões devem estar estruturadas de forma a facilitar a obtenção de "ganhos de troca", funcionando como um conjunto de restrições institucionais, digo, um recurso supra-individual capaz de imputar racionalidade ao aparente caos das preferências individuais e assim, evitar os efeitos deletérios da falta de equilíbrio ${ }^{14}$. Já para o modelo informacional, legisladores buscam não apenas benefícios federais, mas também a possibilidade de "ganhos de informação", partindo do pressuposto que os legisladores que detêm mais

\footnotetext{
${ }^{12}$ Os problemas relacionados à consecução da ação coletiva foram inicialmente elaborados a partir do Teorema de Arrow (não há nenhum modo "natural" de alinhar preferências coletivas como uma função de preferências individuais), e depois analisados sob maior profundidade por Mancur Olson (os indivíduos só cooperarão em relação à ação coletiva se os interesses e benefícios coletivos forem maiores do que os interesses e benefícios não-coletivos). Cf. Arrow (1951); Olson (1965)

${ }^{13}$ Sobre o problema da formação de maiorias cíclicas ver Teorema de Plott (em espaços de escolha multidimensionais, não há virtualmente, nenhum resultado estável sob regra da maioria). $\mathrm{Cf}$ Plott (1967); e Teorema de McKelvey (na ausência de resultados majoritários estáveis sob regra da maioria, quem quer que controle a ordem de votação, pode determinar o resultado final). Cf. McKelvey (1976)

${ }^{14}$ Shepsle (1979) foi o primeiro a instituir o conceito de equilíbrio induzido por estruturas (structure induced equilibrium, ou apenas $S I E$ ) e a provar a existência de cenários institucionais estáveis dentro da legislatura. O ponto de partida para o novo conceito elaborado pelo autor foi a compreensão das instituições enquanto regras formais que dividem o trabalho dentro da legislatura. Neste sentido, ele elege o sistema de comissões como um consistente sistema jurisdicional se subgrupos dentro da legislatura, o qual seria responsável não apenas por escalar os vários legisladores para as diversas comissões, mas também por enumerar os respectivos domínios políticos de cada comissão. Cf. Shepsle (1979).
} 
e melhor informação estão potencialmente mais aptos para pescar seu quinhão dentro do processo distributivo $^{15}$. Finalmente, para a teoria partidária, o sistema de comissões funciona como um agente do partido majoritário, por meio do qual o partido pode influenciar diretamente o processo legislativo e a produção de políticas públicas. A força dos partidos residiria no controle, por parte dos seus membros, da agenda legislativa e do processo de indicações (assignments) para a constituição das comissões ${ }^{16}$.

Pode-se aventar que o papel desempenhado pelas comissões, a sua importância e os padrões de interação entre as comissões e os legisladores são variáveis dependentes da configuração de mecanismos ${ }^{17}$ explicativos escalados por cada uma destas tradições teóricas. Enquanto Shepsle e Weingast (1987) e Weingast e Marshall (1988) têm priorizado em suas análises as respectivas jurisdições de cada comissão e seus poderes de gatekeeping (autoridade para decidir se uma policy será oferecida à apreciação de todos ou revertida ao seu emissor) e ex post veto (autoridade para preservar o status quo inicial frustando qualquer proposta, mesmo depois dela ter sido apreciada e mudada pelo plenário) como as principais engrenagem que explicam o sistema autônomo de cooperação entre os legisladores (log-rolling) ${ }^{18}$. Krehbiel (1991, 2004) tem também focalizado sua atenção sobre

\footnotetext{
${ }^{15} \mathrm{O}$ insight teórico da vertente informacional é que, para além dos que pensam os teóricos distributivos, instituições não servem apenas para resolver questões distributivas, elas também podem ser muito úteis na produção e circulação de informação dentro da Casa, ou mesmo, na ocultação, monopolização e concentração da informação em poucas mãos. Os teóricos informacionais enriquecem a discussão sobre o processo de funcionamento e organização do legislativo na medida em que endogeneizam as variáveis institucionais (vistas não apenas como elementos estruturadores de preferências e políticas, mas também como reflexo das próprias escolhas legislativas) e fazem uso de modelos de informação incompleta que caracterizam não somente o papel da incerteza dentro do processo legislativo, mas também o uso estratégico da informação por parte dos legisladores. Cf. Krehbiel (2004, 1988)

${ }^{16}$ Os teóricos partidários, tal como os distributivistas e informacionais, reconhecem o papel central que o sistema de comissões exerce no legislativo norte-americano, contudo criticam a ênfase excessiva destes últimos sobre a pretensa autonomia das comissões e a dita inviolabilidade de suas decisões (decision-making power committes). Para os teóricos partidários, a crescente centralidade decisória que as comissões vêm ganhando historicamente no legislativo norte-americanos sinaliza não um enfraquecimento dos partidos em detrimento das comissões, mas antes, um complexo processo de delegação de tarefas do partido para as comissões, sem que isto implique, necessariamente em abdicação ou perca de poderes por parte do partido. Cf. Cox e McCubbins (1993)

${ }^{17}$ Por mecanismo compreendo aqui o conceito inicialmente desenvolvido por Jon Elster: mecanismos seriam formulações mínimas enunciadas por cada teoria acerca da composição dos desejos e das crenças dos atores, a partir das quais podemos deduzir como os indivíduos interagem entre si e como respondem às questões externas. Cf. Elster (2000)

${ }^{18}$ Sobre a lógica analíticas das barganhas legislativas ver trabalho pioneiro de Baron e Ferejohn (1989).
}

os arranjos institucionais, contudo combina isso às escolhas dos legisladores e argumenta que os arranjos institucionais têm um efeito ainda maior do que o que é previsto pela literatura distributivistas: eles refletem não só os embates distributivos entre parlamentares, mas também a necessidade de promoção e fomento de especialização e expertise por parte do sistema de comissões como forma de reduzir a incerteza dos resultados. Por outro lado, Cox e McCubbins (1993), contrariando estas interpretações, priorizam outros mecanismos como a estrutura do poder de agenda (agenda power) dos líderes de partido e dos Presidentes da Casa e das comissões, além das regras e estruturas que regulam as escolhas das comissões. Eles concordam que muito do controle da agenda seria descentralizado tal como afirmam distributivistas e informacionais, contudo argumentam que este "controle descentralizado" é atenuado pela influência do partido majoritário no recrutamento dos membros das comissões e pelo controle que os líderes partidários podem ter sobre o destino e a sobrevivência política destes parlamentares.

Embora possamos identificar com relativa facilidade o campo comum de onde partem estas teorias - os postulados da teoria da escolha racional e o núcleo de problemas trazido pela nova tradição institucional -, qualquer semelhança entre estas teorias se esvaece por aqui. Ainda que elas se apóiem sobre um coerente conjunto de aplicações conceituais e instrumentais consensualmente aceitos pela comunidade especializada, elas oferecem explicações mutuamente excludentes sobre o Congresso norteamericano e têm ainda influenciado outras tantas pelo mundo, não obstante as diferenças institucionais entre a democracia norte-americana e os demais modelos de democracia existentes, digo isso pensando, especialmente, no arranjo institucional brasileiro e suas respectivas implicações para o processo decisório dentro do Poder Legislativo.

\section{Processo decisório e procedimentos legislativos}

$\mathrm{Na}$ democracia, os procedimentos que informam a constituição dos órgãos decisórios produzem impactos sobre a sua composição, sobre as estratégias e recursos disponíveis para os diferentes atores e sobre os resultados do jogo político. Estudos comparativos sobre as duas experiências democráticas brasileiras (1946-1964 e pós-1988) têm enfatizado as peculiaridades do processo decisório entre os poderes, antes do que a influência da estrutura institucional, para explicar as diferenças quanto ao desempenho do governo e o comportamento partidário entre 
estes períodos. Estes autores têm argumentado que estas diferenças só podem ser explicadas em função da nova ordem constitucional pós-1988 que teria alterado significativamente o equilíbrio de forças entre os ramos Executivo e Legislativo, se comparada com a Constituição de 1946. O cerne do argumento apóia-se sobre a verificação da ampliação dos poderes legislativos do Executivo que tem início no regime militar e é incorporada pela nova Constituição ${ }^{19}$.

De maneira bastante esquemática, podemos dizer que estes autores elegem três mecanismos institucionais que o Executivo brasileiro pós-1988 tem utilizado para fazer valer suas preferências na arena legislativa. Primeiro, os poderes constitucionais do presidente de legislar, tais como os poderes legislativos pró-ativos, ou seja, aqueles que permitem ao presidente legislar e estabelecer um novo status $q u o$ - os mais comuns são a medida provisória e a capacidade de iniciar nova legislação -, e os poderes legislativos reativos, ou seja, aqueles que permitem ao presidente bloquear a legislação e, como consequiência, defender o status quo contra a maioria legislativa que queira altera-lo - sobretudo, vetos totais ou parciais ${ }^{20}$.

O segundo mecanismo seria a descentralização do processo decisório pelos líderes dos partidos da coalizão majoritária dentro da Casa, o qual permitiria ao presidente, segundo os autores, tanto moldar como até mesmo definir a agenda legislativa. Como exemplo, podemos citar a prerrogativa executiva de iniciar certos tipos de legislação, como a orçamentária e a administrativa, ou ainda o poder de pedir urgência em uma determinada matéria, um mecanismo aproximado à discharge petition, típico do Congresso americano $^{21}$.

O terceiro mecanismo institucional seria a centralização da distribuição de recursos políticos e financeiros pelo Executivo ${ }^{22}$. Os autores afirmam

\footnotetext{
${ }^{19}$ Quanto o impacto da nova ordem constitucional sobre o desempenho do governo e o comportamento legislativo no Brasil ver Figueiredo e Limongi (1999, 2000, 1995).

${ }^{20} \mathrm{O}$ conceito de poderes pró-ativos e reativos foi cunhado inicialmente por Mainwaring e Shugart (1997). De acordo com os autores, existem três categorias amplas de poderes constitucionais dos presidentes: (i) os poderes legislativos pró-ativos - permitem ao presidente estabelecer um novo status quo; (ii) poderes legislativos reativos - permitem ao presidente bloquear a legislação e defender o status quo contra a maioria legislativa que queira mudá-lo; (iii) poderes legislativos de agenda - concede ao presidente iniciativa exclusiva sobre certos tipos de legislação que lhe permite moldar e definir a agenda segundo suas preferências.

${ }^{21}$ A respeito do impacto do poder de agenda sobre o processo legislativo brasileiro ver Amorim Neto, Cox e McCubbins (2003).

${ }^{22}$ Sobre as prerrogativas do Executivo brasileiro sobre o processo orçamentário Cf. Figueiredo e Limongi (2005, 1996); Santos (2003) Pereira (2002).
}

que um dos componentes decisivos do domínio exercido pelo Executivo sobre o comportamento dos parlamentares na Casa é o processo de execução de emendas individuais dos deputados na Lei Orçamentária Anual (LOA), aprovada pelo Congresso e sancionada pelo presidente. Embora os deputados tenham o direito constitucional de formular e aprovar emendas ao PLO previamente elaborado pelo Executivo, é este último, através do Ministério do Planejamento, Orçamento e Gestão, quem de fato executa esse orçamento. $\mathrm{O}$ argumento central desenvolvido pelos autores é que os parlamentares apresentam emendas individuais e coletivas com políticas cujo objetivo é beneficiar suas bases eleitorais e maximizar suas chances de reeleição. Por conseguinte, o Executivo se utilizaria do processo de execução das emendas à LOA para recompensar ou punir os parlamentares, dependendo de sua atuação frente às preferências do Executivo. Em outras palavras: os parlamentares que votam consistentemente de acordo com as preferências sinalizadas pelo Executivo teriam maior probabilidade de verem suas emendas executadas, se de outra maneira, não.

A interpretação que podemos extrair desses esforços explicativos é que o poder institucional de legislar do Executivo aliado ao sistema centralizado de tomada de decisão dentro do Congresso, por um lado, e a distribuição seletiva de benefícios, por outro, impõem limites e restrições ao poder dos parlamentares dentro do próprio Congresso, bem como reduzem a capacidade de ação dos parlamentares ${ }^{23}$. Por conseguinte, a maioria das interpretações acerca do modus operandi do nosso sistema político argumenta que o sistema de comissões no Legislativo brasileiro é eminentemente fraco e débil ${ }^{4}$, na verdade, um reflexo dos poderes constitucionais extraordinários concedidos ao Executivo pela nova Constituição a partir de 1988.

\footnotetext{
${ }^{23}$ A maioria destes estudos têm enfatizado a transição no Brasil de um sistema presidencial faccional para um sistema presidencial de coalizão. Existe nestes trabalhos uma alusão intencional ao estudo de Huber (1996), que empregou a noção de parlamento racionalizado para explicar por que a adoção de normas restritivas para a aprovação de legislação relevante conferiu previsibilidade e coerência à atividade parlamentar na Quinta República Francesa, em comparação com o que havia ocorrido na Quarta República. A principal razão para a adoção destas normas na visão de Huber, foi superar os problemas de coordenação endógenos das bancadas majoritárias, envolvendo a implementação de políticas de interesse nacional mediante a delegação de poderes decisórios ao Executivo. Sobre a adoção de conceito de presidencialismo de coalizão no Brasil Cf. Abranches (1988)

${ }^{24}$ Para ilustrar este argumento conferir passagem: "Because the unusual constitutional [presidential] powers, Brazilian committees are relatively weak, often overruled by party leaders' petitions to discharge bills by means of urgency requests". (Amorin Neto, Cox e McCubbins, 2003).
} 


\section{Discutindo as evidências disponíveis da literatura recente}

Qualquer possível similaridade entre os sistemas políticos norte-americano e brasileiro se restringe ao fato de que ambos são bicamerais em um regime presidencial e estruturados de acordo com um complexo sistema de comissões permanentes. $\mathrm{Na}$ seção anterior foi mostrado, a partir de pesquisas outras, o quanto o Executivo no Brasil possui amplos poderes para defender e perseguir seus interesses no Congresso. Essa dessemelhança com o modelo americano já é por si, um forte indicador de que nenhuma das teorias referidas anteriormente pode, per $s i$, ser capaz de cumprir a tarefa de oferecer caminhos para explicar o funcionamento dos Congressos brasileiro e norte-americano.

A teoria distributivista, tal como formulada inicialmente por Schepsle (1978) e Weingast e Marshall (1988), pressupõe que os parlamentares tenham a capacidade de se auto-selecionar para as comissões de seu interesse e lá permanecer e não ser substituído contra sua vontade. Este não é o caso do sistema de comissões brasileiro. Se as evidências já disponíveis sublinham que a concentração do processo decisório nas mãos do Executivo ou dos líderes dos partidos leva as comissões brasileiras claramente a não ter poder para fazer valer suas preferências, uma das principais condições da teoria distributiva, a saber - autonomia decisória e capacidade de auto-seleção - está sendo violada e, portanto, esta explicação não se aplica ao caso do Congresso brasileiro.

Quanto à adoção dos pressupostos da teoria informacional, a despeito da tentativa elaborada por Pereira e Mueller (2000), esta parece ser isoladamente, tão pouco útil quanto o modelo distributivista para explicar a organização interna do Congresso brasileiro. Os autores reconhecem que qualquer tentativa de explicar o funcionamento do sistema de comissões brasileiro deve levar em conta a enorme preponderância do Executivo sobre a agenda do Legislativo (Pereira e Mueller, 2000), contudo os limites desta adaptação teórica parecem esbarrar sobre evidências empíricas também já disponíveis. A teoria informacional (Krehbiel, 1991) pressupõe que a dita autonomia decisória das comissões cria uma rede de incentivos para que os parlamentares se especializem e criem expertise sobre sua respectiva policy. A hipótese central das teorias distributivista e informacional é a conexão eleitoral entre os parlamentares e seus distritos eleitorais (Gilligan e Krehbiel, 2002), ou seja, parlamentares têm incentivos para estabelecer relações de ganhos de troca com outros parlamentares ou reduzir o grau de incerteza dos resultados via criação de expertise por que ambas as teorias assumem que o objetivo principal de cada parlamentar é perseguir interesses clientelistas para seus distritos e assim, ampliar suas chances de reeleição.

No cenário institucional brasileiro, onde o conhecimento empírico disponível sugere que os parlamentares têm menos autonomia sobre seus destinos eleitorais, em virtude da influência dos líderes de partido sobre suas carreiras, a teoria informacional, a exemplo da teoria distributivista, parece não oferecer instrumentos suficientes que nos ajudem a compreender melhor o funcionamento do sistema de comissões brasileiro. Os pressupostos informacionais perdem suas forças quando submetidos aos altos níveis de rotatividade dentro das nossas comissões e aos seus padrões de nomeação ${ }^{25}$. Dessa maneira, se os deputados não têm nenhuma garantia de que serão alocados nas comissões de sua preferência e se, além de tudo, uma vez assentado em alguma comissão, nada impede que ele venha a ser transferido para qualquer outra comissão quando assim for conveniente ao líder do partido, é incongruente imaginarmos que estes deputados tenham incentivos para se especializarem ou produzirem qualquer forma de expertise.

Um último ponto a destacar são os prognósticos da teoria partidária e suas implicações para o caso brasileiro. A teoria partidária tem recebido atenção especial dos estudiosos do Congresso brasileiro nos últimos tempos. Esta tem sido amplamente recebida no Brasil por que se diz que seus pressupostos são mais condizentes à forma de operação e organização do Legislativo brasileiro ${ }^{26}$. Em direção oposta ao que presumem as teorias distributivista e informacional, os partidos políticos é centralizariam e explicariam a organização interna do Congresso. Fortes evidências empíricas têm sido dadas por estes autores no sentido de verificar o controle do processo legislativo por parte dos líderes e do partido majoritário, contudo mesmo esta mais bem sucedida tentativa de adaptação crítica da teoria não está livre de apresentar algumas

\footnotetext{
${ }^{25}$ De acordo com as regras internas da Câmara, o processo de composição das comissões permanentes deve levar em conta a proporção de representantes de cada partido na Câmara (Art. 25 § 1). Portanto, partidos maiores terão um número maior de membros em cada comissão. Cada deputado só pode participar de uma comissão como membro titular e não há uma regra de senioridade para os postos hierárquicos da comissão, como ocorre nos EUA. Os postos de presidente, vice-presidente, secretário e relator não são cativos. Embora, oficialmente, estas posições sejam escolhidas por voto secreto e maioria absoluta dos votos dos membros da comissão a cada dois anos, na prática elas são determinadas pelos líderes dos partidos. Cf. Santos (2002)

${ }^{26}$ Sobre a aplicabilidade dos pressupostos da teoria partidária ao cenário institucional brasileiro Cf. Figueiredo e Limongi (1996), Santos (2003) e Amorin Neto, Cox e McCubbins (2003).
} 
anomalias quanto à compreensão do sistema de comissões brasileiro.

Para os adeptos da teoria partidária, não há vida política fora do espectro do partido, ou seja, os parlamentares seriam menos atomistas do que pinta o conhecimento vulgar do processo legislativo, tanto no Brasil como nos EUA. Como fortes indícios do poder e do raio de influência do partido sobre seus membros, estes autores argumentam a previsibilidade razoável do comportamento legislativo e a disciplina partidária dos deputados durante as votações no floor. Estudiosos do Congresso Nacional têm engrossado este cordão sob a justificativa de que o modelo partidário se ajusta melhor ao cenário institucional brasileiro, ante o leque de recursos constitucionais concedidos ao Executivo e ao partido majoritário na Casa. Por conseguinte, para estes autores, a dita fragilidade institucional do sistema de comissões brasileiro pode ser explicado por contraposição às prerrogativas constitucionais dos líderes partidários e do presidente da Mesa, os quais são preferidos por estes autores enquanto mecanismos mais eficientes para explicar o padrão de regularidades e o funcionamento do Congresso Nacional.

Mas se é um consenso que as comissões brasileiras deixaram de ser o locus relevante do processo decisório a partir da Constituição de 1988, não passa a ser irracional ou injustificado o interesse do partido majoritário e dos líderes dos partidos sobre o processo de nomeação e indicação para estas mesmas comissões? É importante salientar que embora Cox e McCubbins (1993) mudem seu foco analítico das comissões para o partido majoritário, eles não desprezam o papel exercido pelas comissões no Legislativo americano ${ }^{27}$, pelo contrário, as comissões só seriam objetos de contenda para o partido majoritário em função dos seus poderes institucionais. O que os autores contestam é a suposta hipótese da autonomia das comissões de que falam os teóricos distributivistas e informacionais ${ }^{28}$. Para os teóricos

\footnotetext{
${ }^{27}$ Sobre o papel reservado às comissões pela teoria partidária conferir passagem:

[...] We argued that the majority party caucus adds another layer of structure and process onto the committee structure studies by ShepsleWeingast and Weingast-Marshall. The majority party in the House achieves stable policy outcomes by binding its members to support a specific structure of agenda power represented by the speaker, the committee chairpersons, and the Rules Committee, a structure which then leads to committees choosing policies that, on average benefit majority party members more than minority party members. [...] We largely agreed that much agenda control is decentralized, as in the models of Shepsle-Weingast and Weingast-Marshall, but argued that the exercise of such decentralized agenda control was itself to regulatory efforts by the party leadership and ultimately to restructuring by the majority party's caucus. (grifo do autor) Cf. Cox e McCubbins (2002:23).

${ }^{28}$ Para Schepsle e Weingast (1994) o Congresso americano tem atravessado uma onda de reformas a partir de 1910 que acabaram levando a um modelo de descentralização administrativa e organizacional a favor das comissões e subcomissões, de forma a contrabalancear o poder dos líderes de partido. É neste sentido que os autores chegarão mesmo a falar em uma possível dita inviolabilidade das decisões das comissões a partir de então (decision-making power of committees).
}

da vertente partidária as comissões são agentes do partido majoritário e integram uma complexa rede de delegação de autoridade, em geral, policiada pelos líderes partidários. Nesse sentido, a força do partido majoritário é mensurada menos pela sua coesão ou prerrogativas institucionais, e mais pelo seu sucesso em estruturar um sistema de comissões para seu benefício próprio. Novamente, a teoria parece encontrar alguns obstáculos empíricos para se adaptar ao contexto institucional brasileiro.

\section{0 sistema de comissões e o problema institucional revisitado}

Scholars antigos e modernos concordam que o elemento básico de organização do Poder Legislativo é o sistema de comissões. Não obstante, as comissões brasileiras, ao contrário do que é previsto pela literatura especializada, não cumprem nenhuma destas prerrogativas institucionais ${ }^{29}$ :

(i) não são gatekeepers de suas respectivas jurisdições;

(ii) não são repositórios de expertise política;

(iii) não são incubadores de políticas ou têm este privilégio sensivelmente inibido e;

(iv) não possuem controle sobre a agenda de seus respectivos domínios políticos.

Resta saber, portanto: para quê servem as comissões brasileiras? Se o sistema de comissões brasileiro não converge para nenhum destes poderes estilizados que a literatura especializada denota, então, como explicar sua constância, existência e funcionamento?

Para o novo institucionalismo da teoria da escolha racional, a esfera legislativa compreende um mundo em que os acordos são forjados entre agentes autônomos ${ }^{30}$. Instituições são consideradas aqui como mecanismos imprescindíveis que diminuem os custos de transação ligados à conclusão dos acordos (agreements), de modo a propiciar aos atores os benefícios da troca (deference and reciprocity) sob a adoção de regras estáveis (arrangements) e a resolução de problemas de ação coletiva. Quando um arranjo institucional persiste por um longo período de tempo - longo o suficiente para permitir que os estudiosos possam observá-lo com relativa regularidade e robustez empírica - então, diz-se que esse arranjo, na linguagem institucional, se impõe

\footnotetext{
${ }^{29}$ Para uma pontuação sumária dos vários poderes institucionais dos comitês Cf. Shepsle e Weingast (1987).

${ }^{30}$ Para uma revisão pontual dos principais postulados do novo institucionalismo da teoria da escolha racional Cf. North (1990); Meadwell (2005) e Rua (2000)
} 
per si (self-enforcing) e é ainda à prova de fraudes (cheat-proof). Em outras palavras, diz-se que ninguém tem qualquer incentivo para deixar o contrato ou existe ainda algum mecanismo de coerção endogenous (enforcement).

Argumentar sob evidências empíricas que o sistema político brasileiro admite fortes restrições (constraints) sobre a atuação legislativa das comissões não é o mesmo que explicar por que estas comissões são assim e não de outro modo. À luz dos pressupostos do novo institucionalismo da teoria da escolha racional, instituições são criadas a partir do cálculo estratégico dos atores, logo, é legítimo suspeitar da avaliação depreciativa que a maioria dos analistas políticos fazem acerca das comissões brasileiras. A idéia aqui é explorar o pressuposto de que as comissões brasileiras, enquanto instituições razoavelmente estáveis e regulares, ainda que tenham suas prerrogativas minoradas frente a um Executivo preponderante, devem exercer alguma função ${ }^{31}$ dentro do processo legislativo, pois como observaram Shepsle e Boncheck (1997: 42):

Se as comissões não tivessem nenhuma autoridade, ou se qualquer autoridade que porventura tivessem levasse a pouco impacto sobre as políticas finalmente aprovadas no Congresso ou no sistema político, então praticamente a única coisa que o membro de uma comissão poderia fazer seria listar sua participação em seu currículo junto com sua associação a outros clubes e sociedades honorárias.

Se os poderes institucionais do sistema de comissões brasileiro são reconhecidamente fracos, por que legisladores ditos racionais optam por preservar um arranjo de poder, à primeira vista, assimétrico? Se os pressupostos enumerados pela literatura americana não se ajustam ao caso brasileiro, então como explicar a persistência e o funcionamento dessas comissões? Para quê (ou a quem) elas servem? Enfim, quais são as fundações institucionais do sistema de comissões brasileiro?

\footnotetext{
${ }^{31}$ Embora sejam já bem conhecidos os limites que a idéia de função traz ao campo das ciências sociais, sinto-me tranqüilo para usá-la aqui, sobretudo quando penso que a esfera legislativa pode ser compreendida como um mundo onde as preferências dos atores são consideradas como dadas e inteligíveis e a interação ocorre sob um cenário estável e contratual, digo, um mundo em que os atos dos agentes sociais são tomados evidências do comportamento e podem ser explicados a partir dos elementos anteriores a esses atos (exigências estruturais, processos de socialização, etc.). Sobre os limites do paradigma funcional para as ciências sociais Cf. Boudon (1979) e Giddens (1997).
}

\section{0 esboço de um modelo analítico para o caso brasileiro e algumas hipóteses preliminares}

$\mathrm{O}$ argumento central desenvolvido aqui é que as teorias distributivista, informacional e partidária, não são suficientes para explicar a organização e o funcionamento dessas comissões. O principal ponto a ser destacado é que cada uma destas teorias, isoladamente, concebem um cenário legislativo que não pode capturar de maneira adequada a complexa rede de perspectivas e motivações sob as quais nossas comissões estão assentadas. Sendo assim, o propósito principal desse plano de estudos é contribuir para o desenvolvimento de uma teoria particular que explique as especificidades do caso brasileiro. $\mathrm{O}$ que não quer dizer que esta teoria não incorporará, quando apropriado, os instrumentais e as idéias das teorias já examinadas anteriormente. Tal teoria deverá ter como um de seus pressupostos centrais o fato de o Executivo brasileiro deter significativo poder de influenciar o processo legislativo para assegurar resultados consistentes com suas preferências. Todavia, esta teoria deverá deter-se não apenas nas regras institucionais que determinam a sequiência pela qual passam as propostas, mas também, na forma como estas regras acomodam-se sob o jogo de interesses entre os ramos Executivo e Legislativo ${ }^{32}$.

O modelo que pretendo desenvolver aqui se baseia no trabalho seminal de Shepsle e Weingast (1987), o qual argumenta que o poder de propor e o poder de barrar propostas na comissão (gatekeeping powers) não são suficientes para justificar o poder exercido pelas comissões no Congresso norte-americano. Segundo estes autores, a chave do poder das comissões americanas repousaria na oportunidade que estas possuem de vetar uma proposta após ela ter sido mudada pelo plenário, o ex-post veto. Assim como já foi dito nas seções anteriores, no caso brasileiro, não existe uma comissão de conferência que possa vetar a legislação depois desta ter sido apreciada em plenário (a exemplo do que acontece no sistema de comissões parlamentares norte-americano ${ }^{33}$ ), contudo, se

\footnotetext{
${ }^{32}$ Haggard e McCubbins (2001) têm enfatizado que não basta saber que instituições influenciam os resultados das políticas, é preciso evidenciar, segundo os autores, como e quando essas instituições afetam as políticas.

${ }^{33}$ No sistema de comissões parlamentares norte-americano, o conference committee, responsável por compatibilizar as propostas do Senado e da Câmara, é capaz de vetar uma nova proposta mesmo após ela ter sido analisada pelo plenário e, por isso, pode funcionar como um mecanismo capaz de dissuadir as modificações pretendidas pelo plenário, garantindo que a proposta original não mude para nenhum ponto que seja pior para a comissão do que o status quo, sob pena de vetar a proposta na próxima instância do jogo. Cf. Baron e Ferejohn (1989).
} 
incorporamos para análise os poderes constitucionais do Executivo no processo legislativo, podemos imaginar que as comissões têm sim um importante papel a desempenhar - a depender da homogeneidade ou heterogeneidade de preferências das comissões em relação às preferências do Executivo.

Imaginemos uma legislatura composta por três indivíduos $(A, B$ e $C$ ), dos quais, um $(C)$ tem poder de ex-post veto. Sempre que qualquer um dos indivíduos $A$ e $B$ mandarem uma proposta $X$ para o plenário, esta poderá ser modificada por $C$ para um ponto que $A$ e $B$ consideram pior do que o preferido, ou para o próprio status quo. O poder institucional do ex-post veto aqui, repousa sobre sua capacidade de demover as preferências originais de $A$ e $B$ que, prevendo a possibilidade de verem sua proposta vetada numa próxima sessão, desistem de tentar derrotar as preferências de $C$. Reconsideremos agora o caso brasileiro: é fato que nossas comissões não possuem tal poder de veto, contudo se supomos que uma comissão tem sua composição manipulada para que seu membro mediano tenha alta lealdade ao Executivo, então se pode argumentar que, se a comissão tem preferências muito próximas ao Executivo e se este possui poder de veto, do ponto de vista da natureza seqüencial das instituições legislativas, é como se a comissão também tivesse esse poder. Assim: se o plenário lança ou altera uma proposta que converge para uma posição que se sabe preterida pelo Executivo, este irá vetá-la, demovendo-a para o status quo. Como todos os parlamentares são ditos racionais e podem prever esta ação, eles nem tentam derrotar as preferências do Executivo. Localizadas entre o plenário e o Executivo, as comissões ocupariam aqui uma posição estratégica no jogo legislativo. À sombra da ameaça do veto presidencial, as comissões podem funcionar como agentes do Executivo, impedindo que legislação contrária aos interesses deste venha a plenário.

As considerações acima dão origem a algumas hipóteses que poderão ser confirmadas se as comissões brasileiras funcionarem realmente tal qual uma espécie de ante-sala das prerrogativas de veto do Executivo. As variáveis-chaves deste modelo são as intensidades das preferências das comissões em relação às preferências do Executivo e o grau de representatividade destas comissões, se mais representativas do plenário ou do Executivo. Vejamos:

Hipótese 1 - Comissões são agentes do Executivo e servem para resolver problemas de coordenação dentro da Casa. Se elas são alinhas às preferências do Executivo elas podem, por antecipação, ter poder de veto, se não, não.

As hipóteses que seguem referem-se às motivações dos legisladores frente às prerrogativas constitucionais do Executivo e suas implicações para a agenda legislativa:

Hipótese 2 - o fato de o Executivo possuir exclusividade de iniciativa sobre determinadas áreas, necessariamente, não deve implicar que os resultados finais contrariem as preferências do membro mediano da comissão.

Hipótese 3 - Quanto mais homogêneas as preferências de uma comissão em relação às do Executivo, maior a probabilidade de ocorrer um pedido de urgência, visto que os interesses da comissão teriam menos chances de serem contrariados.

Hipótese 4 - Quanto mais heterogêneas as preferências de uma comissão em relação às do Executivo, maiores as chances de uma proposta tramitar segundo os procedimentos convencionais da Casa.

Hipótese 5 - O índice de aprovação de pedidos de urgência deve ser tão alto quanto mais estável for a base do Executivo dentro da comissão, digo, quando as preferências da comissão e do Executivo forem homogêneas.

\section{À guisa de uma conclusão: elementos e problemas para uma agenda de pesquisa futura}

Finalmente, este artigo tem como objetivo principal, tomar parte no debate sobre a natureza das instituições congressionais brasileiras, e contribuir para o campo de pesquisa atual oferecendo uma revisão da produção recente, com destaque para suas lacunas e insuficiências, de modo a criar condições para o esboço de uma interpretação possível ou mais coerente para a existência e o funcionamento das comissões parlamentares brasileiras. Busca-se com isso não um caminho teórico radicalmente alternativo, não é essa a questão, mas sim, elaborar o que poderia vir a ser um desenho para pesquisas futuras que possam melhor contrabalançar a contribuição da matriz norteamericana, sem perder de vista as especificidades do modelo brasileiro. Nesse sentido, é imprescindível apresentar ainda algumas questões complementares que possam definir mais claramente nossas principais lacunas até o presente momento e/ou aquelas que 
poderiam vir a ser questões sugestivas para o escopo de novas pesquisas ${ }^{34}$ :

a) Há comissões permanentes que sejam preferidas pelo Executivo brasileiro em detrimento de outras? O Executivo brasileiro tem algum interesse sobre comissões especiais?

b) Há alguma relação entre a importância que os congressistas atribuem a uma comissão e a importância que ela pode vir a ter sobre o controle de cargos comissionados?

c) Qual o critério que explica a entrada de um deputado numa comissão? São os méritos? (Qual o nível educacional desses deputados?) Há menos rotatividade nas comissões de baixo impacto externo do que nas comissões de alto impacto? Como os deputados de comissões diferentes ocupam a maior parte do seu tempo dentro das comissões? Eles se preocupam em criar expertise ou especialização? Por que estas instituições nunca foram vítimas de uma reforma política profunda? Que incentivos os deputados têm para preservar o status quo?

d) Qual é a média de rotatividade das comissões brasileiras? Os parlamentares que entram numa comissão são mais fiéis ao Executivo do que os que foram removidos?

e) A Constituição de 1988 concedeu às comissões permanentes o poder de aprovar uma proposta diretamente, sem que seja necessário submetê-la ao plenário (poder conclusivo). Das propostas aprovadas na Câmara entre 1989 e 2006, quantas foram aprovadas pelo uso deste direito sem emendas do plenário? Sobre que temas versavam estas propostas?

\footnotetext{
${ }^{34}$ Nesta última seção serão apresentadas um conjunto de sugestões que, acreditamos, podem (e muitas delas já estão) suscitando pesquisas e reflexões por parte dos cientistas políticos brasileiros. Nesse sentido, o autor assume seu total risco de, em função do próprio crescimento substancial do número de pesquisa na área, eventualmente, deixar de mencionar trabalhos importantes já concluídos sobre o referido tema, tendo em vista que muito destes trabalhos encontram-se ainda sob a forma de dissertações de mestrado ou teses de doutorado ou mesmo ainda sob a forma de papers, vários, aguardando ainda publicação. Por conseguinte, para evitar injustiças desta natureza, optou-se por fazer menção aos trabalhos já publicados sobre a temática. Para uma análise de tentativas pioneiras de oferecer uma explicação e/ ou interpretação para as comissões legislativas, seu desempenho, produção e mediação com os poderes Legislativo e Executivo, Cf.: Anastasia e Inácio (2010); Diaz, Inácio e Rocha (2009); Diniz (2005); Figueiredo (2008); Sáez e Melo (2007) e Lemos (2006). Sobre estudos de comissões específicas, Cf. Pribeiral (1998); Ricci e Lemos (2004); Santos e Almeida (2005). Para uma análise sobre a dinâmica das comissões em nível estadual, Cf.: Rocha e Costa (2012). Dada a importância dos dados oriundos da aplicação deste survey para uma exploração teórico-empírica da dinçamica das comissões legislativas no nível estadual é importante ainda citar o banco de dados originário da pesquisa: Trajetórias, perfis e padrões de interação de legisladores estaduais em doze unidades da Federação promovida pelo Centro de Estudos Legislativos (CEL-DCP-UFMG).
}

f) Qual a composição das comissões constituídas entre o período de 1989 e 2006 ? Seus membros medianos têm um índice alto ou baixo de lealdade ao Executivo? Há divergências quanto a esta composição durante o interregno democrático de 1946 a 1964 ?

g) Qual o total de propostas que tramitam na Câmara entre 1989 e 2006? Qual é a média de propostas iniciadas pelo Executivo, pelo Legislativo e pelo Judiciário? Há diferenças quanto ao tempo médio de sanção de uma proposta se iniciada pelo Executivo, pelo Legislativo ou pelo Judiciário?

h) Quais comissões a Mesa Diretora determina que dêem um parecer sobre as propostas de iniciativa, respectivamente, do Executivo, do Legislativo e do Judiciário?

i) Qual a média de vetos totais ou parciais editados pelo Executivo sobre as propostas enviadas à Câmara?

j) Sobre que temas versam com mais freqüências as propostas iniciadas, respectivamente, pelo Executivo, pelo Legislativo e pelo Judiciário? Podemos falar em uma divisão de trabalho dentro da Câmara de Deputados?

k) Das propostas promulgadas entre 1989 e 2006, quantas receberam pedido de urgência e quantas tramitaram normalmente? As propostas que receberam pedido de urgência, na sua maioria, forma iniciadas por quem? Quem solicitou mais pedido de urgência durante este período? Executivo ou Legislativo?

1) Tendo em vista que a Constituição de 1988 tornou para o Legislativo, relativamente fácil reverter um veto presidencial, dado que isto requer somente maioria absoluta, com que freqüências as legislaturas compostas durante este período têm feito uso deste dispositivo?

m)Sendo nosso regime presidencialista reconhecidamente apoiado sobre a idéia de coalizões móveis, é possível deduzir que as hipóteses enumeradas anteriormente, ainda que sejam corroboradas, podem sofrer alguma alteração a depender se o Executivo possui uma maioria estável na Câmara ou não?

\section{Referências}

Abranches, Sérgio Henrique. 1988. Presidencialismo de coalizão: o dilema institucional brasileiro. Dados, 31(1): 5-34.

Amorim Neto, Octávio; Cox, Gary e McCubbins, Mathew. 2003. Agenda Power in Brazil's Câmara dos Deputados, 1989-98. World Politics, 55(2): 550-578. http://dx.doi.org/10.1353/wp.2003.0023 
Anastasia, Fátima e Inácio, Magna. 2010. Democracia, Poder Legislativo, Interesses e Capacidades. Cadernos ASLEGIS, 40(2): 33-54.

Anastásia, Fátima; Diáz, Ana Maria; Inácio, Mário e Rocha, Maria Moura (orgs.). 2009. Elites Parlamentares na América Latina. Belo Horizonte: Argvmentvm Editora.

Arrow, Kenneth Joseph. 1951. Social Choice and Individual Value. New York: Willey.

Austen-Smith, David e Banks, Jeffrey Scot. 1999. Positive Political Theory I: Collective Preference. Ann Arbor: University of Michigan Press.

Baron, David e Ferejohn, John A. 1989. Bargaining in Legislatures. American Political Science Review, 83(4): 1181-1206. http://dx.doi. org/10.2307/1961664

Bendor, Jonathan e Meirowitz, Adam. 2004. Spatial Models of Delegation. American Political Science Review, 98(2): 293-310. http://dx.doi.org/10.1017/ S0003055404001157

Bhaskar, Roy. 1996. Realismo. In T. Bottomore e W. Outhwaite (orgs.), Dicionário do Pensamento Social do Século XX. Rio de Janeiro: Jorge Zahar Editor.

Boudon, Raymond. 1979. Efeitos Perversos e Ordem Social. São Paulo: Zahar Editores.

Coleman, James Samuel. 1998. Foundations of Social Theory. London: Harvard University Press.

Cox, Gary e McCubbins, Mathew D. 1993. Legislative Leviathan: Party Government in the House. Berkeley: University of California Press.

Cox, Gary e McCubbins, Mathew D. 2002. Bonding, Structure, and the Stability of Political Parties: Party Government in the House. In K. A. Shepsle e B. R. Weingast. Positive Theories of Congressional Institutions. Ann Arbor: University Michigan Press.

DiMaggio, Paul Joseph e Powell, Walter Woody. 1991. The New Institutionalism in Organizational Analysis. Chicago: University of Chicago Press.

Diniz, Simone. 2005. Interações entre os poderes executivo e legislativo no processo decisório: avaliando sucesso e fracasso presidencial. Dados, 48(2): 333-369. http:// dx.doi.org/10.1590/S0011-52582005000200004

Elster, Jon. 2000. Peças e Engrenagens das Ciências Sociais. Rio de Janeiro: Relume-Dumará.

Figueiredo, Argelina. 2008. Instituições Políticas e Governabilidade: desempenho do governo e apoio legislativo na democracia brasileira. In Carlos Ranulfo Melo e Manuel Alcântara Sáez (orgs.), A Democracia Brasileira: balanço e perspectivas para o século 21. Belo Horizonte: Editora UFMG.

Figueiredo, Argelina e Limongi, Fernando. 1999. Executivo e Legislativo na Nova Ordem Constitucional. Rio de Janeiro: FGV.

Figueiredo, Argelina e Limongi, Fernando. 1995. Mudança Constitucional, desempenho do Legislativo e consolidação institucional. Revista Brasileira de Ciências Sociais, 29(12): 175-200.
Figueiredo, Argelina e Limongi, Fernando. 2000. Presidential power, legislative organization, and party behavior in Brazil. Comparative Politics, 32(2): 58-81. http://dx.doi.org/10.2307/422395

Figueiredo, Argelina e Limongi, Fernando. 2005. "Processo Orçamentário e Comportamento Legislativo: Emendas Individuais, Apoio ao Executivo e Programa de Governo". Dados, 48(4): 737-776.

Figueiredo, Argelina e Limongi, Fernando. 1996. Congresso Nacional: organização, processo legislativo e produção legal. CEBRAP - Cadernos de Pesquisa, (5).

Gamm, Gerald e Huber, John. 2002. Legislatures as Political Institutions: Beyond the Contemporary Congress. In Ira Katznelson e Helen V. Milner (orgs.), Political Science: The Estate of Discipline. New York: W. W. Norton, p. 313-341.

Giddens, Anthony. 1997. Política, Sociologia e Teoria Social Hoje: Encontros com o Pensamento Social Clássico e Contemporâneo. São Paulo: Unesp.

Gilligan, Thomas W. e Krehbiel, Keith. 2002. The Gains from Exchange Hypotesis of Legislative Organization. In Kenneth A. Shepsle e Barry R. Weingast (orgs.), Positive Theories of Congressional Institutions. Ann Arbor: University of Michigan Press.

Haggard, Stephan e McCubbins, Mathew. 2001. Political Institutions and the Determinants of Public Policy. In Stephan Haggard e Mathew McCubbins (orgs.), Presidents, Parliaments and Policy. Cambridge: Cambridge University Press.

Hamlin, Cynthia Lins. 2000. Realismo Crítico: Um Programa de Pesquisa para as Ciências Sociais. Dados, 43(2): 277-290. http://dx.doi.org/10.1590/ S0011-52582000000200006

Huber, John. 1996. Rationalizing Parliament: Legislative Institutions and Party Politics in France. Cambridge: Cambridge University Press. http:// dx.doi.org/10.1017/CBO9780511896446

Immergut, Ellen. 1998. The Theoretical Core of the New Institutionalism. Politics and Society, 26(1): 18-25. http://dx.doi.org/10.1177/0032329298026001002

Kiewiet, D. Roderick e McCubbins, Mathew D. 1991. The Logic of Delegation: Congressional Parties and the Appropriations Process. Chicago: Chicago University Press.

Kiewiet, D. Roderick e McCubbins, Mathew D. 1988. Presidential Influence on Congressional Appropiations Decisions. American Journal of Political Science Review, 65(12): 131-143.

Krehbiel, Keith. 1991. Information and Legislative Organization. Ann Arbor: University of Michigan Press.

Krehbiel, Keith. 2004. Legislative Organization. Journal of Economic Perspectives, 18(1): 113-128. http:// dx.doi.org/10.1257/089533004773563467

Krehbiel, Keith. 1988. Spatial Models of Legislative Choice. Legislative Studies Quarterly, XIX(3): 149-179. 
Lecours, André. 2005. New Institutionalism: Issues and Questions. In André Lecours (org.), New Institutionalism: Theory and Analysis. Canada: University of Toronto Press.

Lemos, Leany Barreiro. 2006. El Sistema de Comisiones en el Senado Brasileño: jieraquía y concentración de poderes en la década de 1990. America Latina Hoy, 43(2): 155-182.

Limongi, Fernando. 2003. Formas de Governo, Leis Partidárias e Processo Decisório. BIB - Boletim Informativo e Bibliográfico de Ciências Sociais. São Paulo, 55(2): 07-39.

Limongi, Fernando. 1994. O Novo Institucionalismo e os Estudos Legislativos: a Literatura Americana Recente. BIB - Boletim Informativo e Bibliográfico de Ciências Sociais, 37(1): 1-100. http://dx.doi. org/10.1017/CBO9781139174800

Mainwaring, Scott e Shugart, Matthew S. 1997. Presidentialism and Democracy in Latin América. Cambridge: Cambridge University Press.

Meadwell, Hudson. 2005. Institutions and Political Rationality. In André Lecours (org.), New Institutionalism - Theory and Analysis. Toronto: University of Toronto Press.

McKelvey, Richard. 1976. Intransitivities in Multidimensional Voting Models and Some Implications for Agenda Control. Journal of Economic Theory, 12(2): 472-82. http://dx.doi. org/10.1016/0022-0531(76)90040-5

North, Douglass Cecil. 1990. Institutions, Institutional Change and Economic Performance. Cambridge: Cambridge University Press. http://dx.doi. org/10.1017/CBO9780511808678

Olson, Mancur. 1965. The Logic of Collective Action. Cambridge: Harvard University Press.

Pereira, Carlos. 2002. "Comportamento estratégico em presidencialismo de coalizão: as relações entre o Executivo e o Legislativo na elaboração do orçamento brasileiro". Dados, 45(7): 206-302.

Pereira, Carlos e Mueller, Bernardo. 2000. "Uma teoria da preponderância do Executivo: o sistema de comissões no Legislativo brasileiro". Revista Brasileira de Ciências Sociais, 15(2): 45-67. http:// dx.doi.org/10.1590/S0102-69092000000200004

Plott, Charles. 1967. A Notion of Equilibrium and Its Possibility under Majority Rule. American Political Science Review, 57 (2): 787-806.

Pribeiral, Tatiana. 1998. Comissão de Constituição e Justiça: Uma ilha de Institucionalização no Congresso Nacional. Revista do Legislativo da $A L M G, 24(2):$ 66-82.

Ricci, Paolo e Lemos, Leany Barreiro. 2004. Produção legislativa e preferências eleitorais na Comissão de Agricultura e Política Rural da Câmara dos Deputados. Revista Brasileira de Ciências Sociais. 19(55): 107-129. http://dx.doi.org/10.1590/ S0102-69092004000200007
Rocha, Marta Mendes e Costa, Alessandra. 2012. Percepções dos Deputados Estaduais sobre o Sistema de Comissões das Assembléias Estaduais Brasileiras. Opinião Pública, 18(2): 278-308. http://dx.doi. org/10.1590/S0104-62762012000200002

Rua, Maria das Graças. 2000. Escolha Racional e Novo Institucionalismo: Notas Introdutórias. In Maria das Graças Rua e Maria Izabel Valadão (orgs.), O Estudo da Política: Tópicos Selecionados. Brasília: Editora Paralelo 15.

Santos, Fabiano. 2003. Patronagem e Poder de Agenda na Política Brasileira. In Fabiano Santos. O Poder Legislativo no Presidencialismo de Coalizão. Belo Horizonte: Editora UFMG; Rio de Janeiro: IUPERJ.

Santos, Fabiano. 2002. Partidos e Comissões no Legislativo de Coalizão. Dados, 45 (2): 237-264. http:// dx.doi.org/10.1590/S0011-52582002000200003

Santos, Manoel Leonardo Wanderley Duarte. 2006. As Teorias Positivas sobre a Organização do Legislativo $e$ as Explicações sobre o Congresso Nacional. Dissertação de mestrado em Ciência Política, Universidade Federal de Pernambuco.

Santos, Fabiano e Almeida, Acir. 2005. Teoria Informacional e a Seleção de Relatores na Câmara dos Deputados. Dados, 48 (4): 693-735. http://dx.doi. org/10.1590/S0011-52582005000400001

Shepsle, Kenneth. 1979. Institutional Arrangements and Equilibrium in Multidimensional Voting Model. American Journal of Political Science, 23(4): 27-60. http://dx.doi.org/10.2307/2110770

Shepsle, Kenneth A e Boncheck, Mark S. 1997. Analyzing politics: rationality, behavior, and institutions. Nova York: W. W. Norton and Company.

Shepsle, Kenneth e Weingast, Barry. 1994. Positive Theory of Congressional Institutions. Legislative Studies Quarterly, XIX(1): 149-179. http://dx.doi. org/10.2307/440423

Shepsle, Kenneth e Weingast, Barry. 1987. The Institutional Foundations of Committee Power. American Political Science Review, 81(1): 37-55. http://dx.doi.org/10.2307/1960780

Shepsle, Kenneth. 1978. The Giant Jigsaw Puzzle: Democratic Committee Assignments in the Modern House Chicago: University of Chicago Press.

Weingast, Barry e Marshall, William. 1988. The Industrial Organization of Congress. Journal of Political Economy, 91(3): 132-163. http://dx.doi. org/10.1086/261528

Weyland, Kurt. 2002. Limitations of Rational-Choice Institutionalism for the Study of Latin American Politics. Studies in Comparative International Development, 37(1): 57-85. http://dx.doi.org/10.1007/ BF02686338 